Petersen, H. (1972). Giardiasis (Lambliasis). Scandinavian Journal of Gastroenterology, 7, Suppl., 14.

E. Sagaró, E. Blanco, T. Fragoso, and

C. CASTAÑEDA

Institute of Gastroenterology, Department of Public

Health, Havana, Cuba.

Correspondence to Dr. E. Sagaró.

\section{Bacterial colonization of infants raised in incubators and under radiant heaters}

During the past several years open radiant heaters have been used with increasing frequency in neonatal intensive care units. While this has permitted greater patient accessibility, exposure of the infants to room air raises the possibility of increased incidence of bacterial colonization and clinical infection, especially among those likely to have impaired host defence mechanisms. We have compared the prevalence of bacterial colonization of the skin and anterior nares and clinical infection among infants cared for under radiant heaters with those raised in standard incubators.

\section{Materials and methods}

Infants admitted to the study were (i) raised exclusively either in an Isolette incubator or under a radiant heater for the first $\mathbf{7 2}$ hours of life; (ii) free of proven or suspected infection and received no systemic antibiotics; (iii) born of mothers who had no infection and no prolonged rupture of membranes ( $>18$ hours); and (iv) free of major congenital anomalies or conditions requiring surgical intervention. 58 infants meeting these criteria were studied, with 34 being raised in C-86 Isolette incubators (I) and 24 under $\mathrm{KDC}$ radiant heaters (RH). A thermoneutral environment was maintained in all cases. Selection of infants for I or RH care was based on availability of equipment and the type of handling required by medical and nursing staff. In general, those requiring a greater degree of attention were raised under RH (Table I). Apgar scores were equivalent in both groups. None of the I infants required either ventilatory assistance or umbilical arterial catheterization: in the RH group 6 required ventilatory assistance and 9 underwent umbilical arterial catheterization on the first day of life. 8 of these 9 infants had bacitracin ointment applied topically to the umbilicus once a day.
Table 1 Details of infants in incubators and under radiant heaters

\begin{tabular}{|c|c|c|}
\hline & Incubator & Radiant heater \\
\hline Number (male/female) & $34(14 / 20)$ & $24(14 / 10)$ \\
\hline Vaginal delivery & 28 & 18 \\
\hline Caesarean section & 6 & 6 \\
\hline \multicolumn{3}{|l|}{ Umbilical arterial } \\
\hline catheterization & 0 & 9 \\
\hline Assisted ventilation & 0 & 6 \\
\hline Topical bacitracin to umbilicus & 0 & 8 \\
\hline $\begin{array}{l}\text { Systemic antibiotics } \\
\text { Median (and range) }\end{array}$ & $\mathbf{0}$ & 0 \\
\hline gestational age $(w)$ & $\begin{array}{l}38 \\
(30-41)\end{array}$ & $\begin{array}{l}33 \cdot 5 \\
(28-42)\end{array}$ \\
\hline \multicolumn{3}{|l|}{ Median (and range) } \\
\hline birthweight (g) & $\begin{array}{l}2170 \\
(1190-4540)\end{array}$ & $\begin{array}{l}1620 \\
(870-4000)\end{array}$ \\
\hline \multicolumn{3}{|l|}{ Apgar score } \\
\hline 1 minute & $\begin{array}{r}8 \\
10\end{array}$ & $\begin{array}{l}7 \cdot 5 \\
9\end{array}$ \\
\hline $\begin{array}{l}\text { Median duration of rupture } \\
\text { of membranes (h) } \\
\text { Median duration of labour (h) }\end{array}$ & $\begin{array}{l}9 \\
6\end{array}$ & $\begin{array}{l}3 \cdot 75 \\
6 \cdot 3\end{array}$ \\
\hline
\end{tabular}

Infants in both groups were admitted with approximately equal frequency to one of two adjacent rooms, neither of which had a circulating air system. Before handling of infants, all staff members gowned and washed to the elbows with hexachlorophane (pHisohex). None of the infants was bathed with soaps containing antimicrobial agents before completion of the study. Cultures were taken with a dry cotton swab daily for the first 3 days of life from the anterior nares, umbilicus, and groin. Other studies, such as blood and urine cultures and blood counts were performed when clinically indicated.

Swabs were streaked on sheep blood agar plates, and were incubated aerobically at $37^{\circ} \mathrm{C}$ for 48 hours. Subcultures were done as necessary either on blood agar or MacConkey plates. Organisms were identified by standard bacteriological methods, previously described (Evans et al., 1970). In addition, blood agar plates were exposed to air daily for one hour at mattress level in both study groups.

\section{Results}

None of the 58 infants developed either clinical or laboratory evidence of infection. One infant with respiratory distress syndrome in the RH group died after completion of the study; signs of infection were not observed at necropsy, and post-mortem blood cultures were negative.

Bacterial colonization rates of the umbilicus, groin, and anterior nares during the first 3 days of life are shown in Table 2. The most commonly observed organism, Staphylococcus epidermidis, was seen with approximately equal frequency at all sites in both groups. The prevalence rate for this organism ranged from $17 \%$ to $65 \%$. 
Table 2 Bacterial colonization at three sites on days 1, 2, 3 in infants nursed under radiant heaters or in incubators

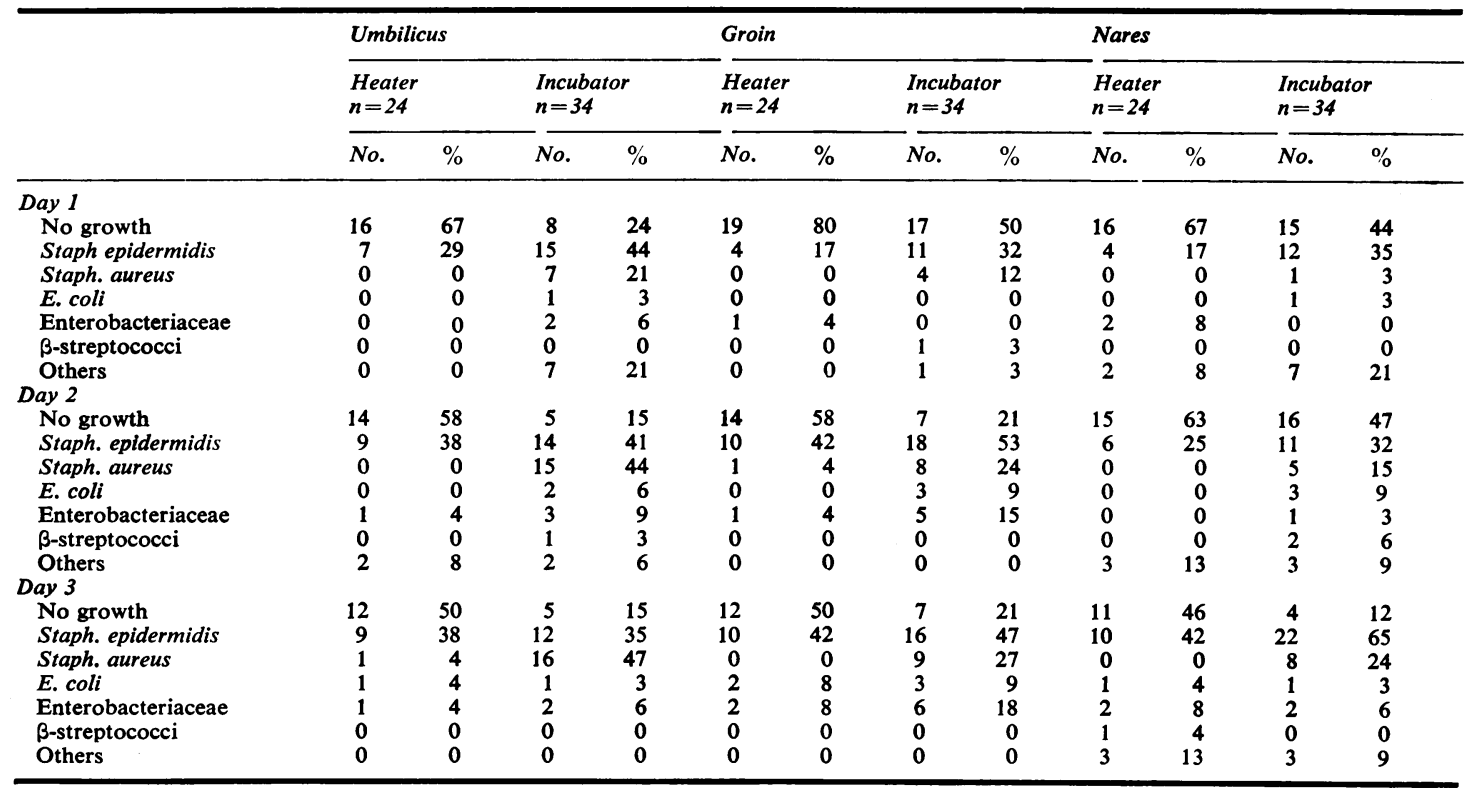

In the I group, umbilical colonization with Staph. aureus rose from $21 \%$ on day 1 to $47 \%$ on day 3 . Colonization of the groin with this organism rose from $12 \%$ on day 1 to $27 \%$ on day 3 , and nasal colonization increased from $3 \%$ to $24 \%$ over this period. In contrast, only one of the RH infants was colonized with Staph. aureus. This difference is significant for the umbilicus on all 3 days (day 1, $\chi^{2}=4.79, \mathrm{P}<0.05$; day $2, \chi^{2}=12.08, \mathrm{P}<0.0005$; day $\left.3, x^{2}=10 \cdot 51, P<0.005\right)$, and for the groin on day $3\left(\chi^{2}=7 \cdot 52, \mathrm{P}<0 \cdot 01\right)$.

The 8 RH infants who received topical applications of bacitracin ointment to the umbilicus were similar to the 16 who did not receive this medication with respect to colonization with organisms other than Staph. aureus.

When the former 8 infants are eliminated differences in colonization of the umbilicus remain significant on days 2 and $3\left(x^{2}=8 \cdot 09, \mathrm{P}<0.005\right.$ and $\chi^{2}=6 \cdot 36, \mathrm{P}<0 \cdot 025$, respectively), as do differences in colonization of the groin on day $3\left(x^{2}=4 \cdot 70\right.$, $P<0.05)$.

The predominant organism detected on exposed blood agar plates in both groups was Staph. epidermidis. Staph. aureus was detected only once in the RH group (day 3), but was detected twice on plates exposed in incubators on day 1 , four times on day 2 , and twice on day 3 .

\section{Discussion}

Continuous exposure of compromised newborn infants to room air did not lead to increased rates of bacterial colonization or clinical infection. On the contrary, decreased rates of bacterial colonization occurred in these infants compared with infants receiving standard incubator care. This was in spite of the fact that nursery air (or air immediately surrounding the radiant heater) was not recirculated and filtered (Musch et al., 1971). In addition, it may be assumed that the lower birthweights and gestational ages of the RH infants placed them at greater risk of developing infection than the I group.

The reduced prevalence of colonization with Staph. aureus in the RH group may be at least in part due to topical use of bacitracin in 8 infants. However, the fact that the remaining 16 were also not colonized with Staph. aureus suggests that other factors may be involved. It is possible that radiant heat may alter skin physiology (e.g. $\mathrm{pH}$ and fatty acid content), or may be associated with drying, so that susceptibility to colonization with Staph. aureus is decreased. 


\section{Summary}

To assess the effect of open radiant heaters on bacterial colonization of neonates, 24 infants were raised under radiant heaters and 34 in standard incubators. Cultures of the nose, groin, and umbilicus were taken daily for the first 3 days of life. For infants raised in incubators, colonization rates with Staph. aureus ranged up to $47 \%$. Among infants raised under radiant heaters ( 8 of whom had topical antibiotics applied to the umbilicus), only one was colonized with this organism. Even if the 8 treated infants were excluded, the prevalence of Staph. aureus was significantly greater at the umbilicus and groin in infants raised in incubators.

\section{References}

Evans, H. E., Akpata, S. O., and Baki, A. (1970). Factors influencing the establishment of the neonatal flora. I. The role of host factors. II. The role of environmental factors. Archives of Environmental Health, 21, 514-519 and 643648.

Musch, B., Adams, J., and Sunshine, P. (1971). An air curtain incubator for use in an intensive-care nursery. Journal of Pediatrics, 79, 1024-1030.

Chia T. Chang, Leonard Glass, Hugh E. Evans, and SOPHIE H. PIEROG

Department of Pediatrics, Jewish Hospital and Medical Center of Brooklyn, 555 Prospect Place, Brooklyn, N.Y. 11238, USA.

Correspondence to Dr. C. T. Chang. 